\title{
Evolution of the Number of Students in Elementary and Secondary School in Portugal and Population Ageing
}

\author{
Cecília Rosa' ${ }^{1}$ Edgar Pereira ${ }^{2}$ \\ ${ }^{1}$ Department of Mathematics, Instituto Politécnico da Guarda, Guarda, Portugal \\ ${ }^{2}$ Department of Mathematics, Universidade Federal do Rio Grande do Norte, Natal, Brasil \\ Email: cecirosa@ipg.pt
}

How to cite this paper: Rosa, C. and Pereira, E. (2017) Evolution of the Number of Students in Elementary and Secondary School in Portugal and Population Ageing. Open Journal of Social Sciences, 5, 112-127. https://doi.org/10.4236/jss.2017.57008

Received: May 15, 2017

Accepted: July 10, 2017

Published: July 13, 2017

Copyright ( $) 2017$ by authors and Scientific Research Publishing Inc. This work is licensed under the Creative Commons Attribution International License (CC BY 4.0).

http://creativecommons.org/licenses/by/4.0/ (c) (i) Open Access

\begin{abstract}
In this work, we present an application of a mathematical model structured in classes (see [1]) for the study of the influence of population ageing in the evolution of the number of students in elementary school and in secondary school in Portugal, from 1995/96 to 2014/15 (see [2]). Based on historical data, some scenarios of projection are presented, with the aim of quantifying the young student population and its relation with the structure of the population age for the next school years in Portugal (from 2016/2017 to 2020/2021), in the various study cycles. Furthermore, we make a comparative analysis between the projection results presented here and in references [3] and [4]. The dynamic of the model comprises two stages: the first one represents the flow of students that go from one school year to the next, as well as the flow of students that enter or leave the educational system in a certain cycle of studies. The second stage represents the flow of students that go to the next cycle of studies. The simulations were done using Matlab.
\end{abstract}

\section{Keywords}

Mathematical Model, Structured Class, Student Population Evolution, Population Ageing

\section{Introduction}

The Portuguese Educational System comprises pre-elementary, elementary, secondary and higher education. Elementary schooling corresponds to compulsory education, incorporating the applicable criteria that follow; it lasts nine years (from $1^{\text {st }}$ to $9^{\text {th }}$ grade), and incorporates students from 6 to 15 years of age. It is structured in three sequential cycles, being the first cycle of four years $\left(1^{\text {st }}\right.$, 
$2^{\text {nd }}, 3^{\text {rd }}$, and $4^{\text {th }}$ grades $)$, the second one of two years ( $5^{\text {th }}$ and $6^{\text {th }}$ grades $)$, and the third cycle of three years $\left(7^{\text {th }}, 8^{\text {th }}\right.$, and $9^{\text {th }}$ grades). Secondary school, which we designate $4^{\text {th }}$ cycle, has three school years (from $10^{\text {th }}$ to $12^{\text {th }}$ grade), and it is organized in different forms, with mutually pervious courses, oriented either to further education or working life ([2] [4]).

The objective of the present work is to give some projections of the impact of population ageing in the student population in Portugal, according to the structure described above for the next years. The tool used is a version of the model developed in [1] and the main data were collected from the publications of governmental organisms ([2] [4] [5] [6]). We make simulations based on historical data and the projection for the next years.

In Section 2 we present the model used to project the variation of student population. In Section 3, first we make simulations of the model using the historical data, then we describe the evolution of students in primary education (from $1^{\text {st }}$ to $9^{\text {th }}$ grade), and in secondary education (from $10^{\text {th }}$ to $12^{\text {th }}$ grade), in Portugal, from 1995/16 to 2014/15. Then, we give projections for the next years (from 2015/2016 to 2020/2021). Due to a lack of official data we consider the year 2015/2016 in the projections. We make a comparative study with the official projections ([3] [4] [7]). In Section 4 we show the implications of the population ageing both in the historical data and projections ([6]). We used Matlab for the simulations and for the projections we used Excel to show the numerical results together with the graphics.

\section{The Model}

We use a simplified version of the model developed in [1]. Such model considers two dynamics, one for the movement of students in a study cycle and another for the transfers between schools. Here we need to consider only the first dynamics, considering that a student change to another school is not relevant in this study. The population of students is represented by a vector of size $s$

$$
X(t)=\left[x_{1}(t), x_{2}(t), \cdots, x_{s}(t)\right]^{\mathrm{T}},
$$

where each element $x_{i}(t)$ is the student population in the $i=1, \cdots, s$ year of the study cycle.

The change of the student population, that is the dynamics, is considered in two stages, first we divide the student population of a cycle in approved and flunked. This is represented by two vectors:

$$
A(t)=\left[a_{1}(t), a_{2}(t), \cdots, a_{s}(t)\right]^{\mathrm{T}}, R(t)=\left[r_{1}(t), r_{2}(t), \cdots, r_{s}(t)\right]^{\mathrm{T}}
$$

in which the components $a_{1}(t), a_{2}(t), \cdots, a_{s}(t)$ and $r_{1}(t), r_{2}(t), \cdots, r_{s}(t)$ are respectively the number of approved and the number of flunked in each cycle years in the end of the academic year $t$.

The students who are approved in the last year of a cycle are those who finish the cycle, so they are considered in the second stage. If it is the last year of the last cycle the student ends this study cycles. The number of students approved in 
the next year $t+1$ is given by the vector

$$
Y(t+1)=R(t)+N A(t) \text { or } Y(t+1)=X(t)-A(t)+N A(t),
$$

where

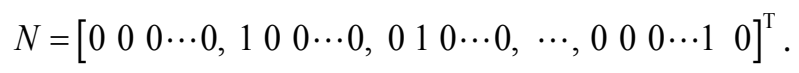

Thus,

$$
N A(t)=\left[0, a_{1}(t), \cdots, a_{s-1}(t)\right]^{\mathrm{T}} .
$$

The components $y_{i}(t+1), \quad i=1, \cdots, s$, of the vector $Y(t+1)$ are the sum of flunked with the approved in the year $t$.

In the second stage we consider the recruiting of new students for the first year and the students who enter or leave for another reason, this includes those who return to the studies and the dropout students. Again we consider two vectors:

$$
G(t)=\left[g_{1}(t), g_{2}(t), \cdots, g_{s}(t)\right]^{\mathrm{T}},
$$

and

$$
B(t+1)=\left[b_{1}(t+1), b_{2}(t+1), \cdots, b_{s}(t+1)\right]^{\mathrm{T}},
$$

to represent, respectively, the students who leave the school in the year $t$ and the students who enter the school in the year $t+1$. This second stage is given by the vector

$$
W(t+1)=B(t+1)-G(t) .
$$

We join these two stages and we obtain the equation for the student population in the year $t+1$

$$
X(t+1)=Y(t+1)+W(t+1) .
$$

In order to make simulations of the model we need an algorithm to implement in a computer program. An appropriated algorithm is to compute the student population of a year $t+1$ in terms of the population of the year $t$.

For this we consider the following matrices:

$$
T=\operatorname{diag}\left(t_{1}, t_{2}, \cdots, t_{s}\right) \text { and } D=\operatorname{diag}\left(d_{1}, d_{2}, \cdots, s_{s}\right) \text {, }
$$

having for each year of the study cycle the estimated rates, respectively, of approved students and of students who leave the school, in the year $t$, and the matrix

$$
E=\operatorname{diag}\left(e_{1}, e_{2}, \cdots, e_{s}\right),
$$

having the estimated rate of the new students in the next year $t+1$. So we can write the model by

$$
X(t+1)=X(t)+(I-T+N T+E-D) X(t) .
$$

The implementation of the model is done by the next algorithm, which gives us projections for a period of $\mathrm{n}$ years, starting in the year $t$.

Algorithm: Given $n$, let $P(0)=X(t)$, for some academic year $t$, then for 
$j=1, \cdots, n$ do

$$
P(j+1)=P(j)+\left(T_{m}+N T_{m}+E_{m}-D_{m}\right) P(j)
$$

where $T_{m}, E_{m}, D_{m}$ and $S_{m}$ are diagonal matrices, whose elements are the means of students who are approved, join the school, finish their studies and leave the school, respectively, for each academic year during the period.

\section{Evolution of the Student Population}

The historical data used in this section have, as the main source, the data base of the information system of the General Direction of Statistics of the Ministry of Education and Science in Portugal (DGEEC). The data obtained refer to the types of training offers for young people in continental Portugal since the academic year 1995/96 until the academic year of 2014/2015, and we have chosen a joint analysis of private and public schools data, in regular and artistic teaching in Continental Portugal ([2] [5]).

First we present the evolution of the number of young students enrolled in basic and secondary schooling who have attended regular and artistic studies in continental Portugal from 1995/96 to 2014/2015, grouped by school year and level, regarding the number of students enrolled, approved and flunked, published in [2] and [5].

After that a projection of the number of students enrolled in continental Portugal for the next years (2015/16-2020/21) is done, and four projection scenarios are presented. Scenario 1 refers to projections presented by DGEE in [4] and scenarios 2, 3 and 4 (blue, pink and red) result from the application of the algorithm (1). It must be noted that the data of 2014/2015 are not projections, but are, in fact, official data from Education Statistics for scenarios 2, 3 and 4. Since the data for the school year of 2015/2016 are not available, they are considered in the projection.

We have observed that for each academic year, at the end of the last year of a cycle, the students approved go to the first year of the next cycle, which will be considered the entries in the next cycle. Besides that, for every study cycle and based on the historical data presented, it was possible to build a group of projections in various scenarios, for a period of 6 academic years: from 2015/2016 to 2020/2021.

Next we describe the methodology used to construct the four projection scenarios:

- Scenario 1 (green) refers to the projections presented by DGEE in [4], based on the projection model described in [3], having as assumptions the gradual implementation of compulsory schooling, the demographic constraints, the rate of approved and flunked students in different school years. These assumptions are supported by census data and also, in more recent data, of age distribution in each school year, for each training offer.

Scenarios 2, 3 and 4 result from the application of the model described in the previous section, by applying the Algorithm (1) and they take into account the 
historical data (1995/96 - 2014/15) that refer to the rates of transition, retention, dropping and graduation in different school years for each study cycle.

- Scenario 2 (blue) considers the mean values in the whole evolution period, from 1995/96 a 2014/15.

- Scenario 3 (pink) considers the mean values in the last 10 years, from 2005/06 a 2014/15.

- Scenario 4 (red) considers the mean values in the last 5 years, from 2010/12 to $2014 / 15$.

The projections are presented in graphs and tables. The graphs show the projection results for each academic year, by study year and total. Tables show only projection's total values.

\subsection{Cycle $1-1^{\text {st }}$ to $4^{\text {th }}$ Grade}

On the first curricular year of the first cycle the retention rate is $0 \%$, which means that all students are approved and go to the $2^{\text {nd }}$ year of the next academic year [2] [5].

Figure 1 shows the evolution in the number of students enrolled, approved and repeaters of the $1^{\text {st }}$ cycle of basic school since the academic year of 1995/96 until 2014/15.

A decrease of students in all years can be seen. In 1995/96 503,049 students were enrolled, in 2000/01 they were 485,517, in 2005/06, 465,238, in 2010/11, 435,162 and in 2014/15, there were 391,870 students enrolled.

It can also be noticed that the number of students that go to the next year decreases a little, showing a steady tendency, and that the number of repeaters decreases slightly throughout the whole period from 1995/96 to 2014/15.
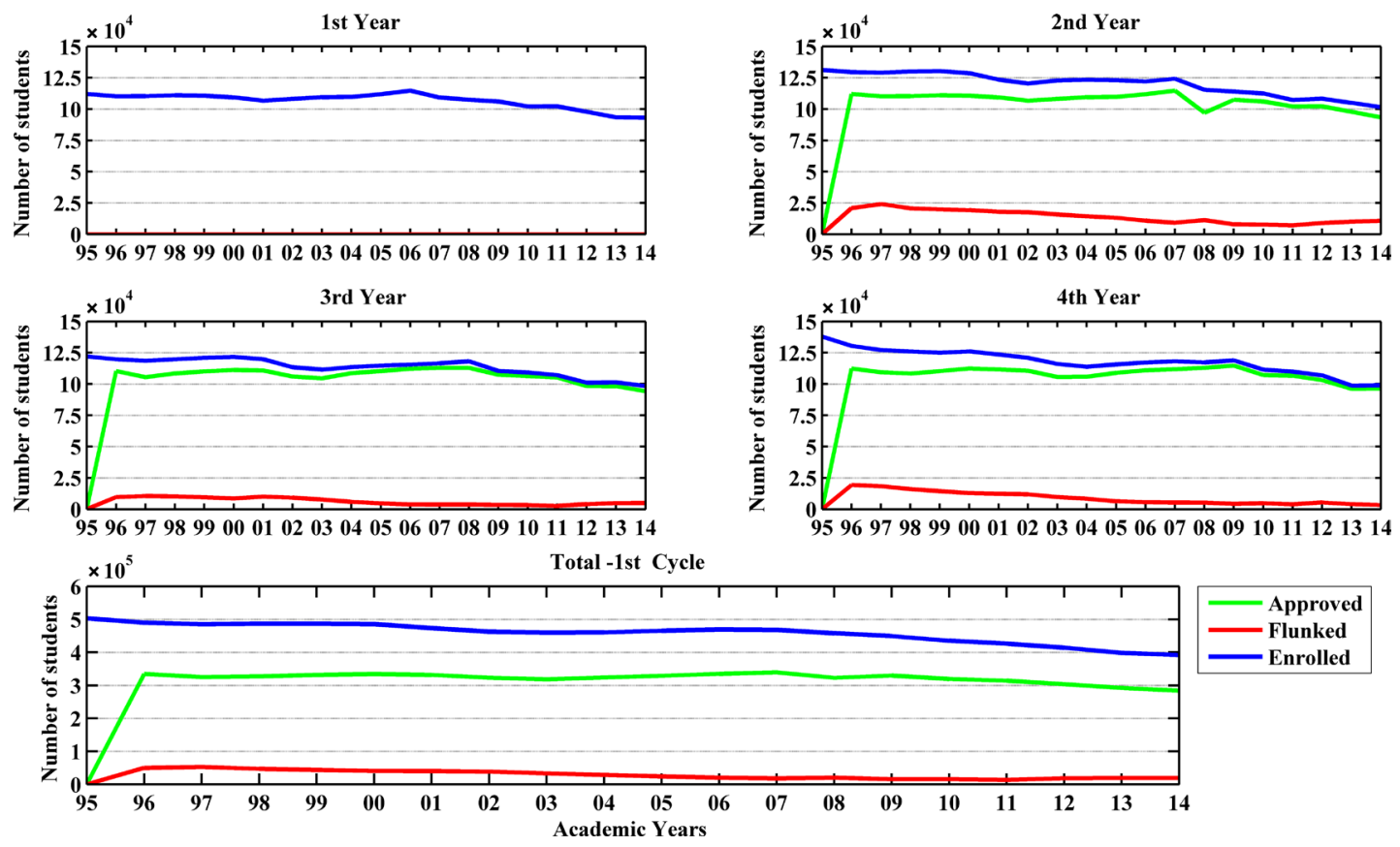

Figure 1. Evolution of the number of students enrolled, approved and repeaters in the first cycle of basic school (1995/96-2014/15). 
Figure 2 shows the four scenarios of projections for the 1st cycle of basic school $\left(1^{\text {st }}, 2^{\text {nd }}, 3^{\text {rd }}\right.$, and $4^{\text {th }}$ years $)$ for the period of 2015/16 until 2020/21.

The four scenarios of projections reveal a general tendency of decrease in the number of students in all years. Furthermore, it can be predicted that this decrease will be a little sharper on $1^{\text {st }}$ grade.
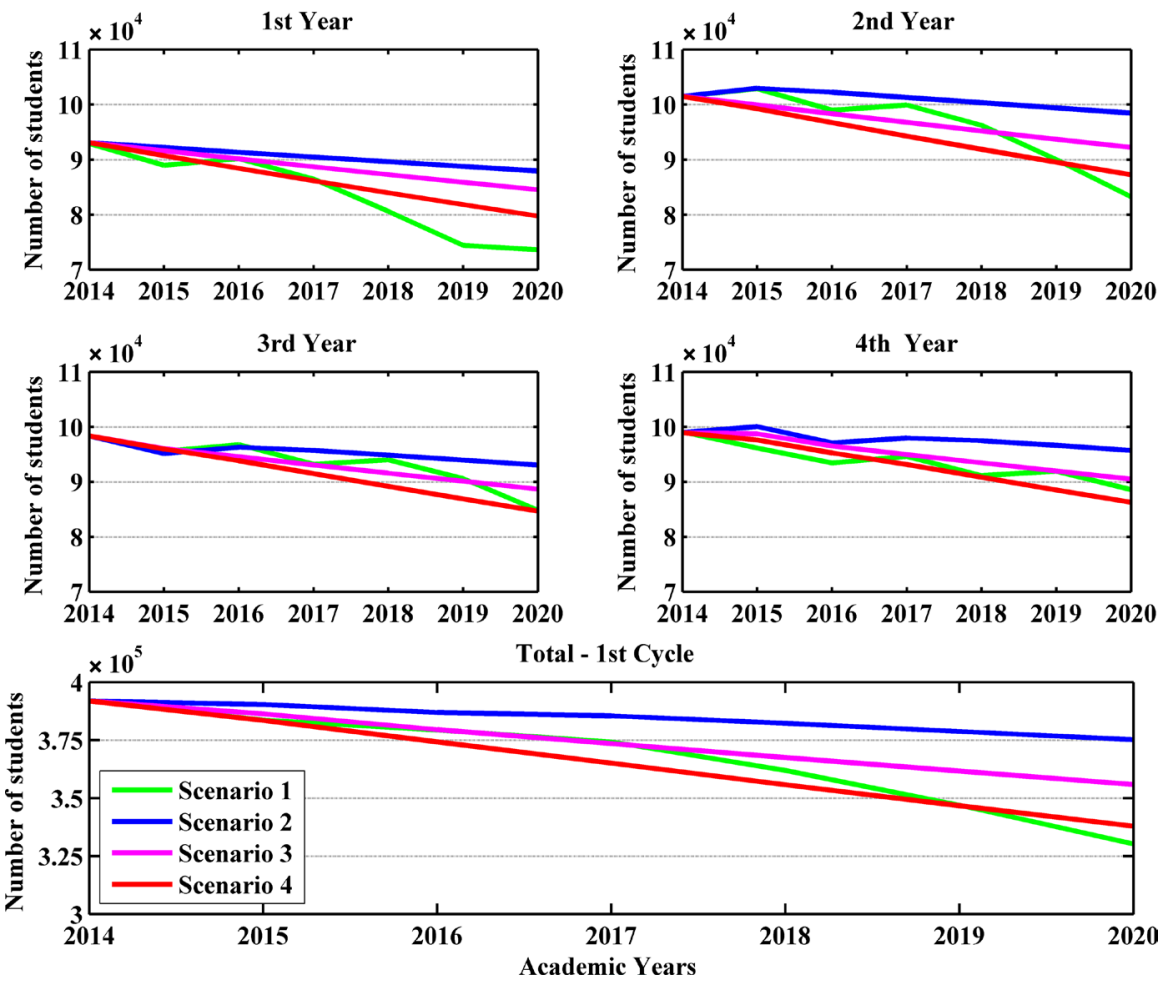

Figure 2. Projection of the number of students for the $1^{\text {st }}$ cycle of basic school (2015/162020/21).

Table 1 shows the total numbers for Cycle 1 presented in the projections of Figure 2.

Table 1. Projection totals - Cycle 1.

\begin{tabular}{ccccccc}
\hline Years & $\mathbf{2 0 1 5 / 1 6}$ & $\mathbf{2 0 1 6 / 1 7}$ & $\mathbf{2 0 1 7 / 1 8}$ & $\mathbf{2 0 1 8 / 1 9}$ & $\mathbf{2 0 1 9 / 2 0}$ & $\mathbf{2 0 2 0 / 2 1}$ \\
\hline Scenario 1 & 383,554 & 379,383 & 374,214 & 361,936 & 346,925 & 330,235 \\
Scenario 2 & 390,366 & 386,966 & 385,453 & 382,293 & 378,754 & 375,183 \\
Scenario 3 & 386,298 & 379,525 & 373,482 & 367,524 & 361,656 & 355,880 \\
Scenario 4 & 383,531 & 374,249 & 365,058 & 355,793 & 346,729 & 337,892 \\
\hline
\end{tabular}

The green scenario is the worst case with fewer 53,319 students in the end of the period, the blue is the best with fewer 15,183 students, the pink and red show fewer 30,418 and 45,639 fewer students, respectively.

\subsection{Cycle $2-5^{\text {th }}$ to $6^{\text {th }}$ Grade}

Figure 3 shows the evolution for the $2^{\text {nd }}$ cycle of basic school from 1995/96 to $2014 / 15$. 

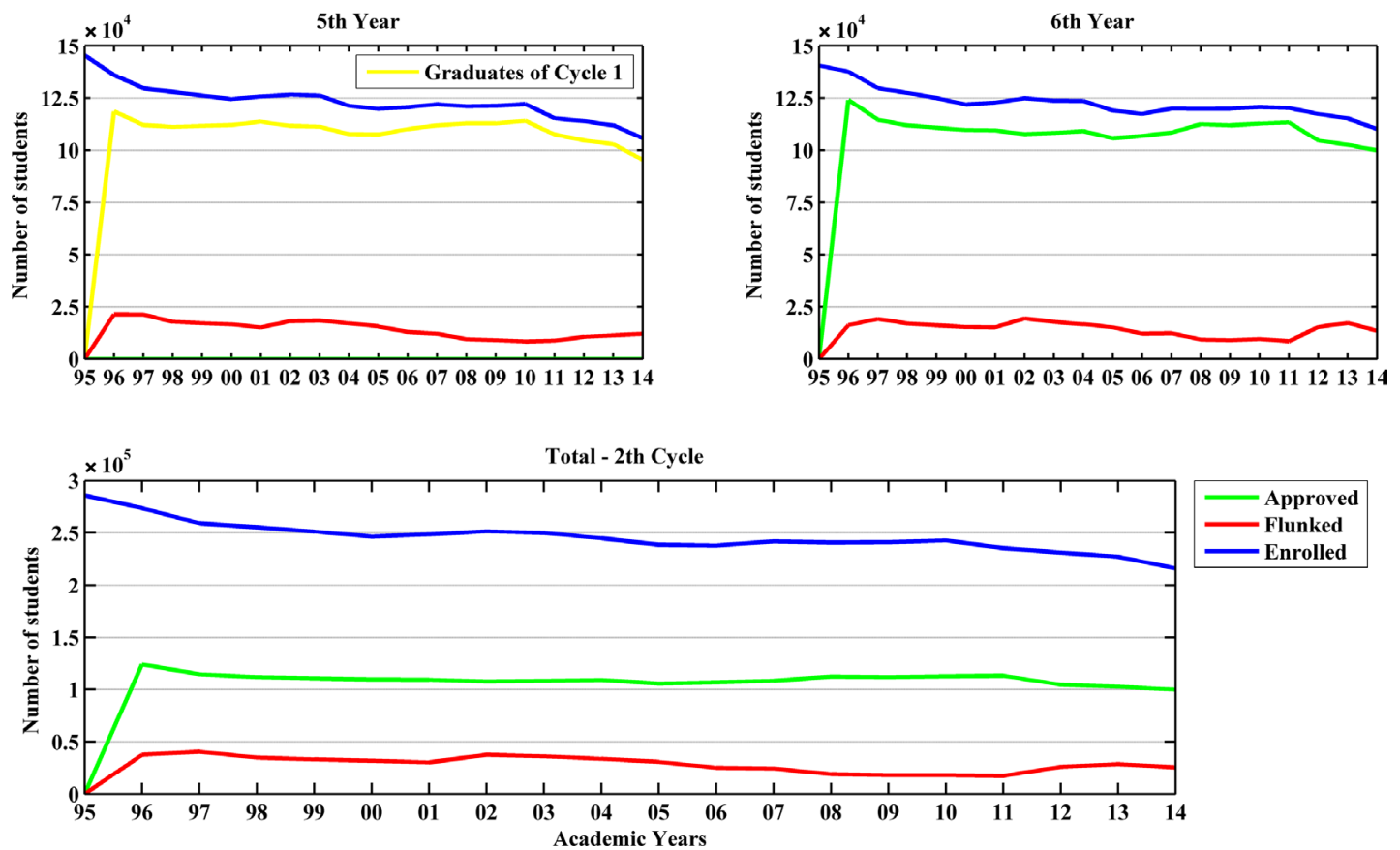

Figure 3. Evolution of the number of students enrolled, approved and repeaters in the 2nd cycle of basic school (1995/96-2014/15).

For the $2^{\text {nd }}$ cycle of basic school a general decrease in the numbers of enrolled students can also be seen, with emphasis in last year of the cycle.

In total we have observed that in 1995/96 285,944 students were enrolled, in 2000/01 they were 246,336 students, in 2005/06, 238,570 were enrolled, in $2010 / 11$, there were 242,704 and in 2014/15, 215,937 students were enrolled.

The number of students who go to the next year of a cycle keeps more or less constant throughout the period. The number of repeaters has had an increase from 2011/12 on.

Figure 4 shows the four scenarios of projections for the $2^{\text {nd }}$ cycle of basic school ( $5^{\text {th }}$ and $6^{\text {th }}$ years).

For the $2^{\text {nd }}$ cycle of basic school it can also be predicted a generalized decrease in the number of students, although not as sharp as in the $1^{\text {st }}$ cycle.

Table 2 shows the total figures for Cycle 2, presented in the projections of Figure 4.

The red scenario is the worst case with fewer 22,107 students in the end of the period; the blue is the best with fewer 9053 students; the green and pink show fewer 16,551 and 16,119 students, respectively.

\subsection{Cycle 3-7th to $9^{\text {th }}$ Grade}

Figure 5 shows the evolution for the 3rd cycle of basic school from 1995/96 to 2014/15.

Regarding the numbers of students enrolled, a recovery that reverses the decreasing tendency can be seen since 2008/09.

In total we observe that in 1995/96 405,870 students were enrolled, in 2000/01, 357,900 , in 2005/06, 342,865, in 2010/11, 343,034, and in 2014/15, 334,225. 

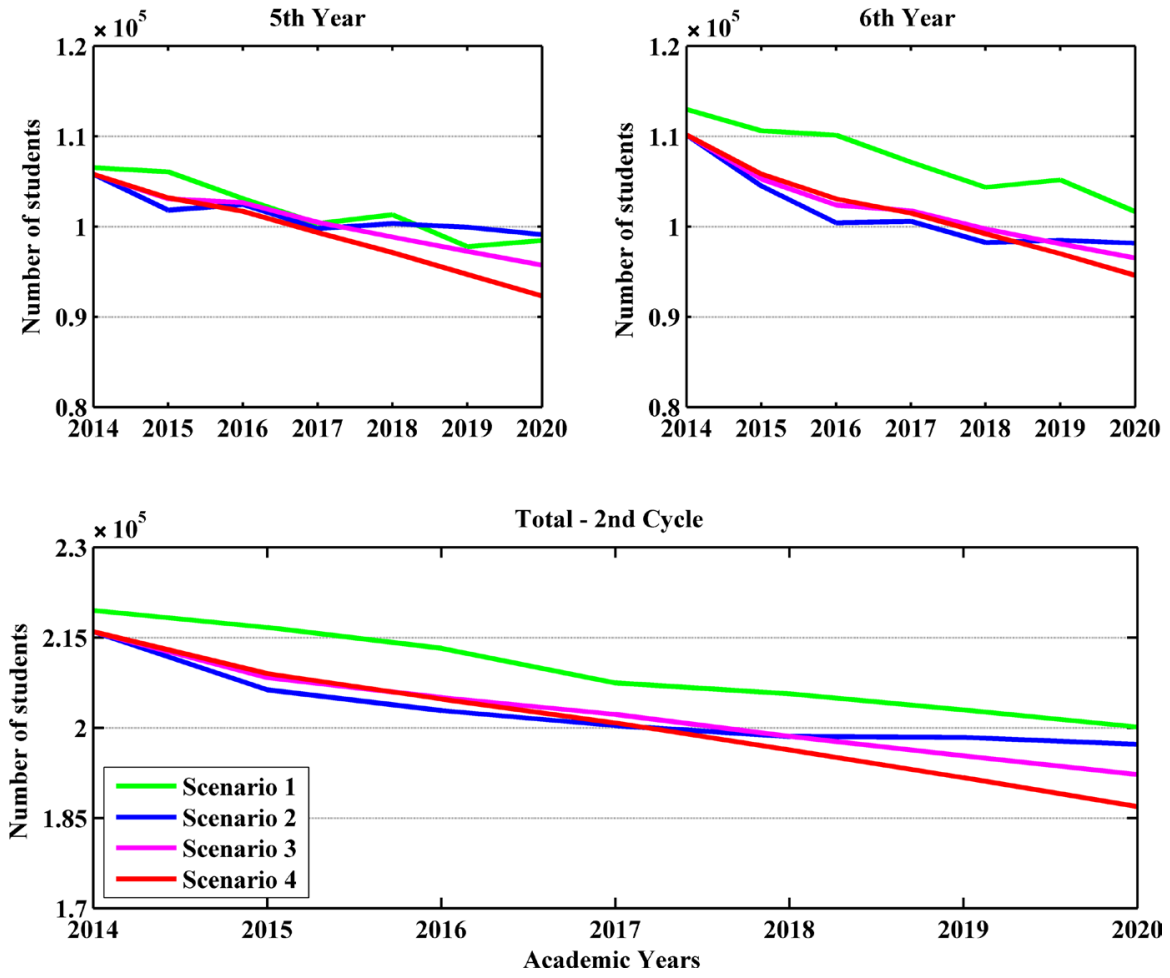

Figure 4. Projection of the number of students for the 2nd cycle of basic school (2015/162020/21).

Table 2. Projection totals - Cycle 2.

\begin{tabular}{ccccccc}
\hline Years & $\mathbf{2 0 1 5 / 1 6}$ & $\mathbf{2 0 1 6 / 1 7}$ & $\mathbf{2 0 1 7 / 1 8}$ & $\mathbf{2 0 1 8 / 1 9}$ & $\mathbf{2 0 1 9 / 2 0}$ & $\mathbf{2 0 2 0 / 2 1}$ \\
\hline Scenario 1 & 216,660 & 213,201 & 207,439 & 205,639 & 202,944 & 200,109 \\
Scenario 2 & 206,295 & 202,848 & 200,334 & 198,535 & 198,395 & 197,242 \\
Scenario 3 & 208,331 & 205,016 & 202,212 & 198,561 & 195,333 & 192,212 \\
Scenario 4 & 208,988 & 204,752 & 200,800 & 196,301 & 191,677 & 186,881 \\
\hline
\end{tabular}
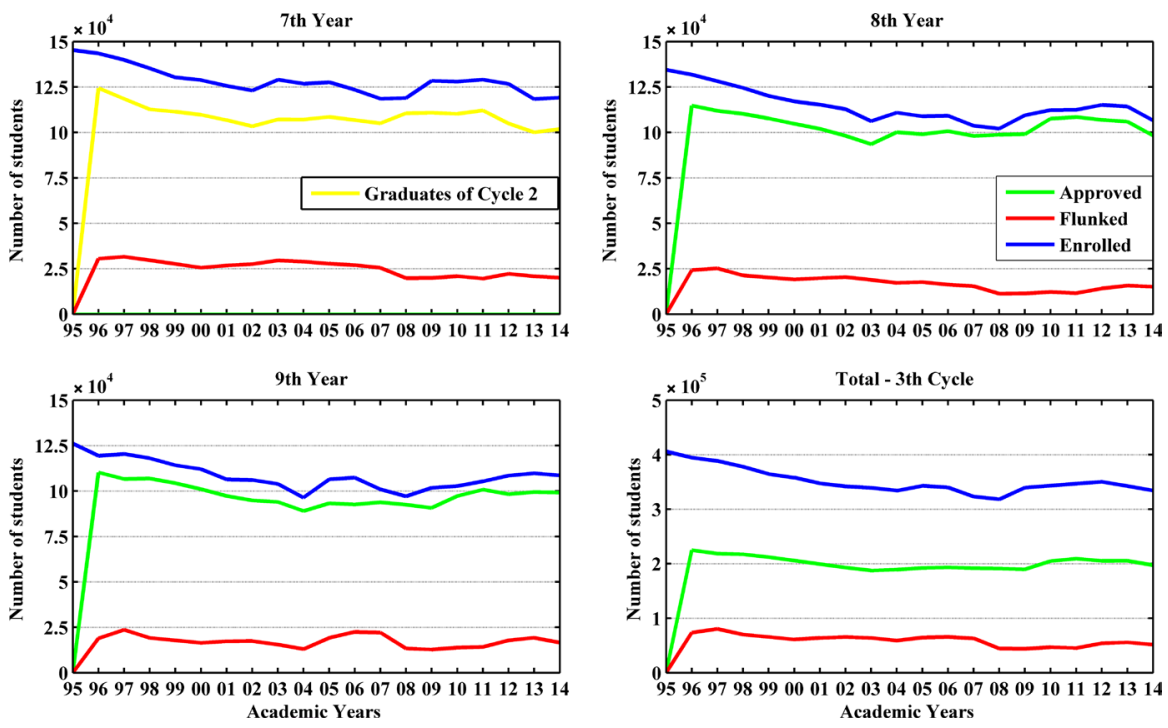

Figure 5. Evolution of the number of students enrolled, approved and repeaters in the $3^{\text {rd }}$ cycle of basic school (1995/96-2014/15). 
The number of students that go the next year and the number of repeaters follow the same tendency. These results are mainly due to the extension of compulsory education.

Figure 6 shows the four scenarios of projections for the $3^{\text {rd }}$ cycle of basic school $\left(7^{\text {th }}, 8^{\text {th }}\right.$ and $9^{\text {th }}$ years $)$.

The projections for the $3^{\text {rd }}$ cycle follow the tendency of previous cycles.

Table 3 shows the total numbers for the $3^{\text {rd }}$ cycle presented in the projections of Figure 6.
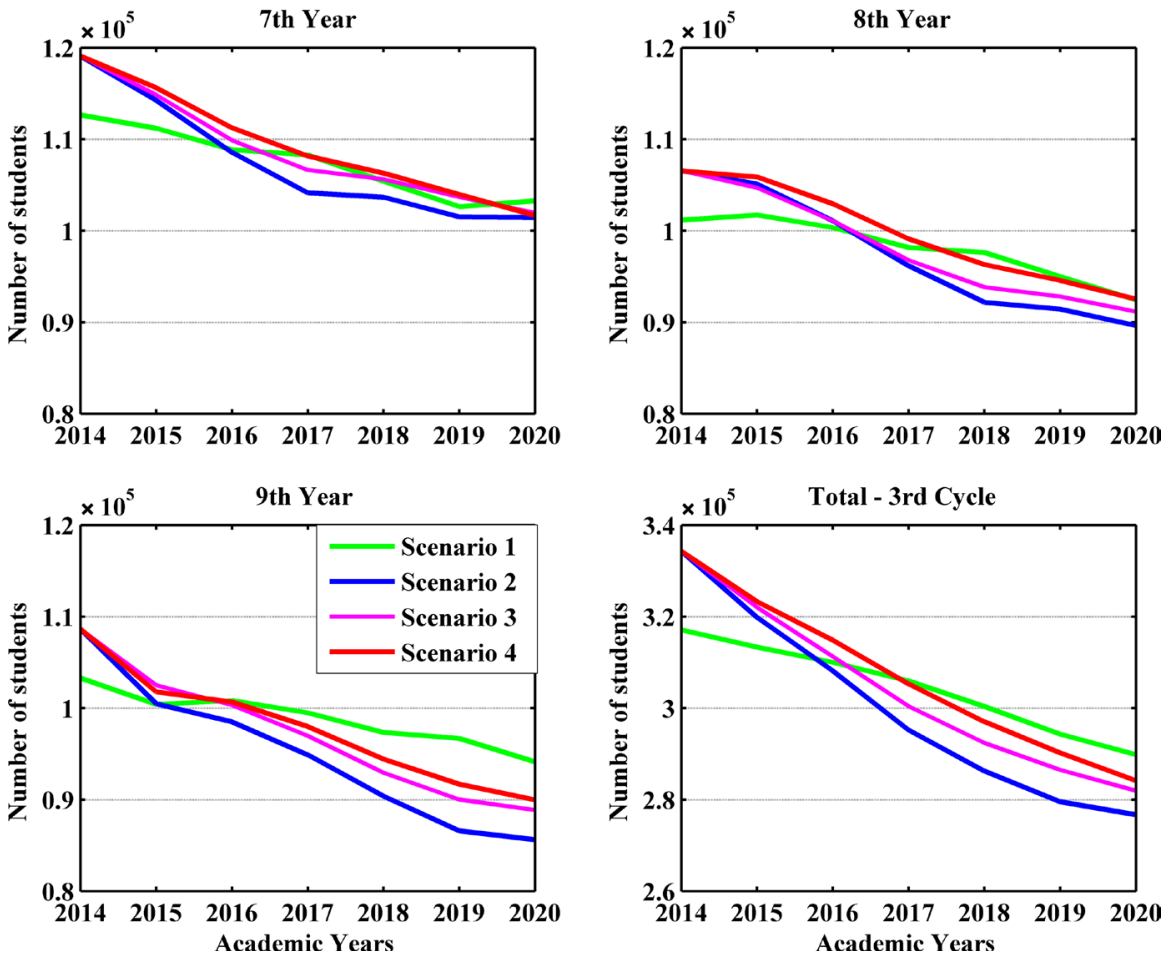

Figure 6. Projection of the number of students for the $2^{\text {nd }}$ cycle of basic school $(2015 / 16$ 2020/21).

Table 3. Projection totals - Cycle 3.

\begin{tabular}{ccccccc}
\hline Years & $\mathbf{2 0 1 5 / 1 6}$ & $\mathbf{2 0 1 6 / 1 7}$ & $\mathbf{2 0 1 7 / 1 8}$ & $\mathbf{2 0 1 8 / 1 9}$ & $\mathbf{2 0 1 9 / 2 0}$ & $\mathbf{2 0 2 0 / 2 1}$ \\
\hline Scenario 1 & 313,314 & 309,995 & 305,925 & 300,353 & 294,296 & 289,838 \\
Scenario 2 & 319,796 & 308,122 & 295,187 & 286,206 & 279,526 & 276,689 \\
Scenario 3 & 321,998 & 311,258 & 300,372 & 292,375 & 286,486 & 281,932 \\
Scenario 4 & 323,253 & 314,825 & 305,241 & 297,002 & 290,222 & 284,153 \\
\hline
\end{tabular}

The blue and pink scenarios are the worst cases with fewer 43,107 and 40,066 students, respectively, in the end of the period. The best is the green one, with fewer 23,476 students, the red scenario shows fewer 39,100 students.

\subsection{Cycle $4-10^{\text {th }}$ to $12^{\text {th }}$ Grade}

Figure 7 shows the evolution for secondary school from 1995/96 to 2014/15.

Regarding the number of students enrolled, it can be noted that until 2008/09 
there was a sharp decrease, and from then on, the numbers were relatively stabilized.
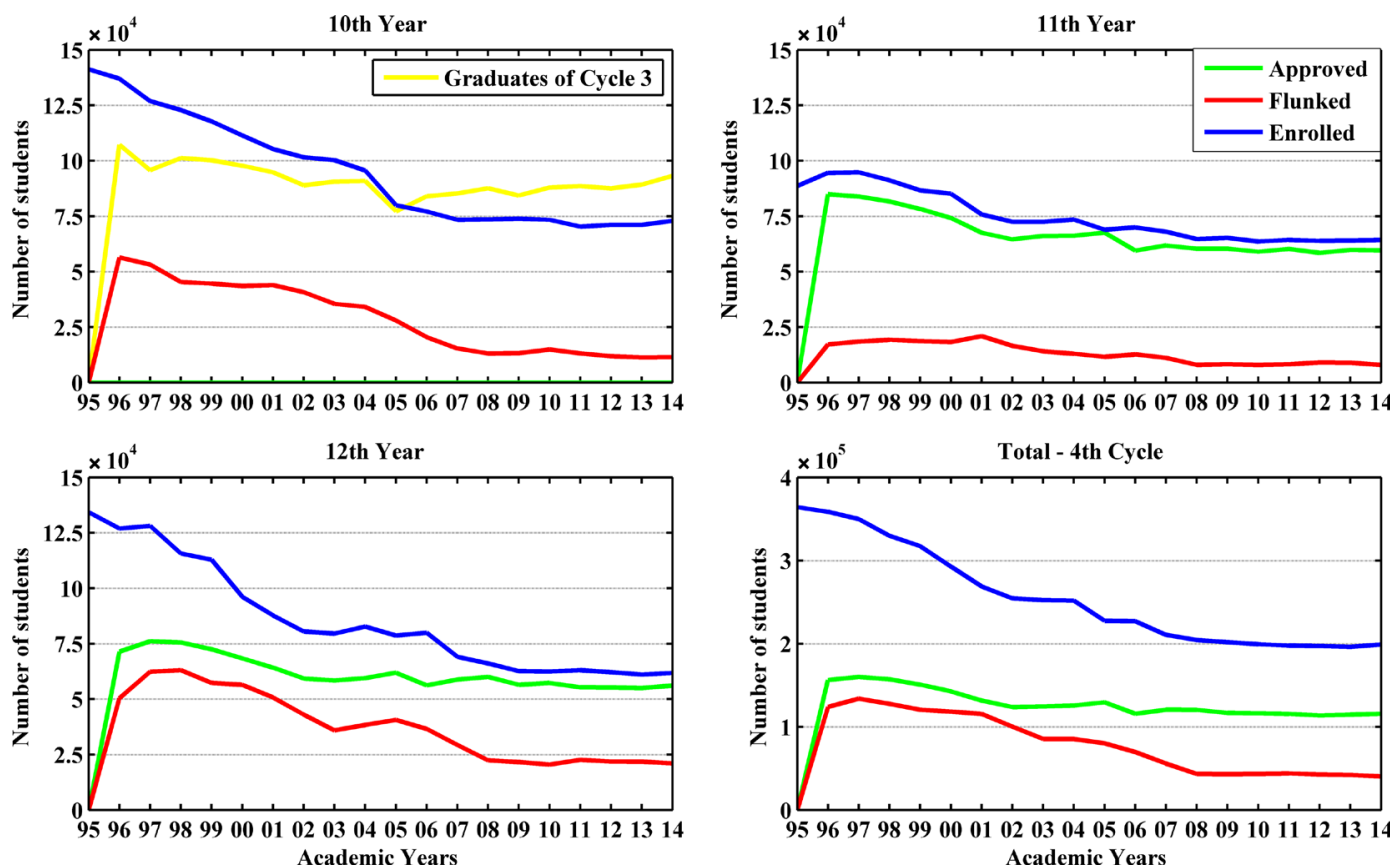

Figure 7. Evolution of the number of students enrolled, approved and repeaters in secondary school (1995/96-2014/15).

In total we observe that in 1995/96 364,157 students were enrolled, in 2000/01, 292,613 , in 2005/06, 227,475, in 2010/11, 199,376, and in 2014/15, 198,901.

This sharp decrease regarding the number of students enrolled in secondary school is also due to the existence of other training offers, such as professional and vocational courses.

Figure 8 shows the four scenarios of projection for the $3^{\text {rd }}$ cycle of basic school $\left(7^{\text {th }}, 8^{\text {th }}\right.$, and $9^{\text {th }}$ years $)$.

For the $4^{\text {th }}$ cycle, secondary school, the projection is of a recovery in the number of students until 2017/18, and then a decrease until 20120/21, reversing the tendencies observed in the $1^{\text {st }}$ and $2^{\text {nd }}$ cycles of basic school.

Table 4 shows the total figures for Cycle 4 (Secondary school) presented in the projections of Figure 8.

Table 4. Projection totals - Cycle 4.

\begin{tabular}{ccccccc}
\hline Years & $\mathbf{2 0 1 5 / 1 6}$ & $\mathbf{2 0 1 6 / 1 7}$ & $\mathbf{2 0 1 7 / 1 8}$ & $\mathbf{2 0 1 8 / 1 9}$ & $\mathbf{2 0 1 9 / 2 0}$ & $\mathbf{2 0 2 0 / 2 1}$ \\
\hline Scenario 1 & 203,374 & 204,505 & 205,790 & 203,546 & 201,029 & 198,473 \\
Scenario 2 & 213,925 & 213,791 & 216,457 & 210,314 & 202,781 & 194,610 \\
Scenario 3 & 204,584 & 201,941 & 199,923 & 192,868 & 186,484 & 179,995 \\
Scenario 4 & 200,972 & 196,444 & 192,955 & 186,452 & 181,710 & 176,097
\end{tabular}

The red and pink scenarios are the worst cases with fewer 24,875 and 24,589 students, respectively, in the end of the period. The green is the best with fewer 4901 students; the blue shows fewer 19,315 students. 

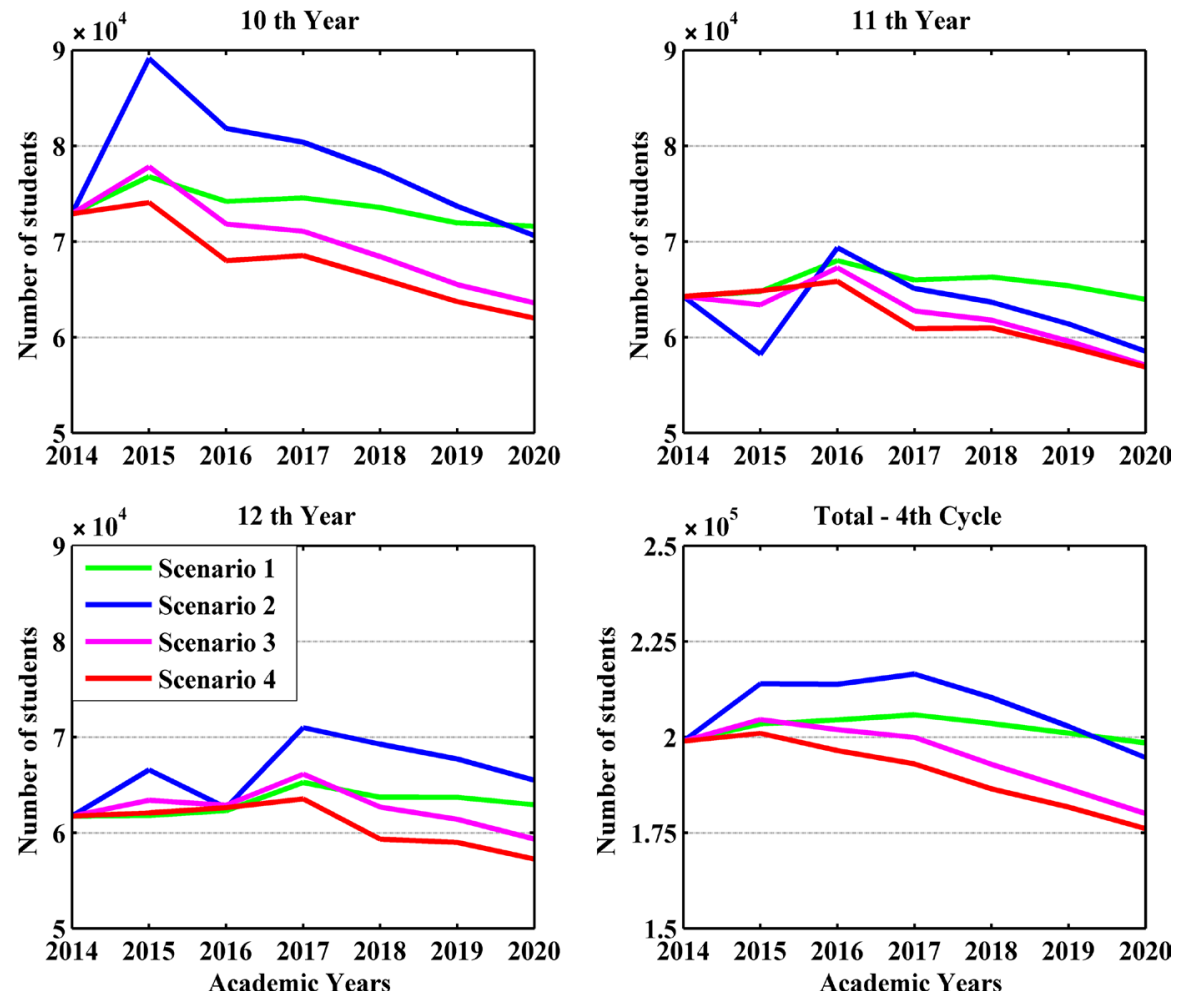

Figure 8. Projection of the number of students for the $4^{\text {th }}$ Cyle - secondary school $(2015 / 16-2020 / 21)$.

\section{The Impact of Population Ageing}

We consider here the relationship of the ageing and the decrease in the number of students, although it is expected that this is directly proportional, other factors as the economic situation of the country also have a strong contribution to such decrease.

The statistical data presented in this section, about the annual estimates on the resident population and their projections, were obtained from the National Institute of Statistics (INE) [6]. In the period 2008-2015 the data about the resident population are historical and, in the period 2016-2021 they are projections done by (INE) [6]. INE presents three projection scenarios of the population: high, central and low. We have opted to present only the central scenario.

Regarding the students data, they are the ones from the previous section. Until the school year of 2014/15 they are real data and, from 2015/16 to 2020/21 they are projections.

\subsection{Evolution of Resident Population}

Figure 9 shows the evolution of the older population in Portugal considering the ranges of the ages $65-69,70-74,75-79$ and $80-84$ years [6]. According the projections for the next years the older population will continue to grow. This has combined factors: the decrease of natality rate and the increase of life expectancy.

In Figure 10 is presented the evolution for young populations (children and 
teenagers), 5 - 9, 10 - 14, and 15 - 19 years [6]. It can be observed that the contention is greater in the younger classes.

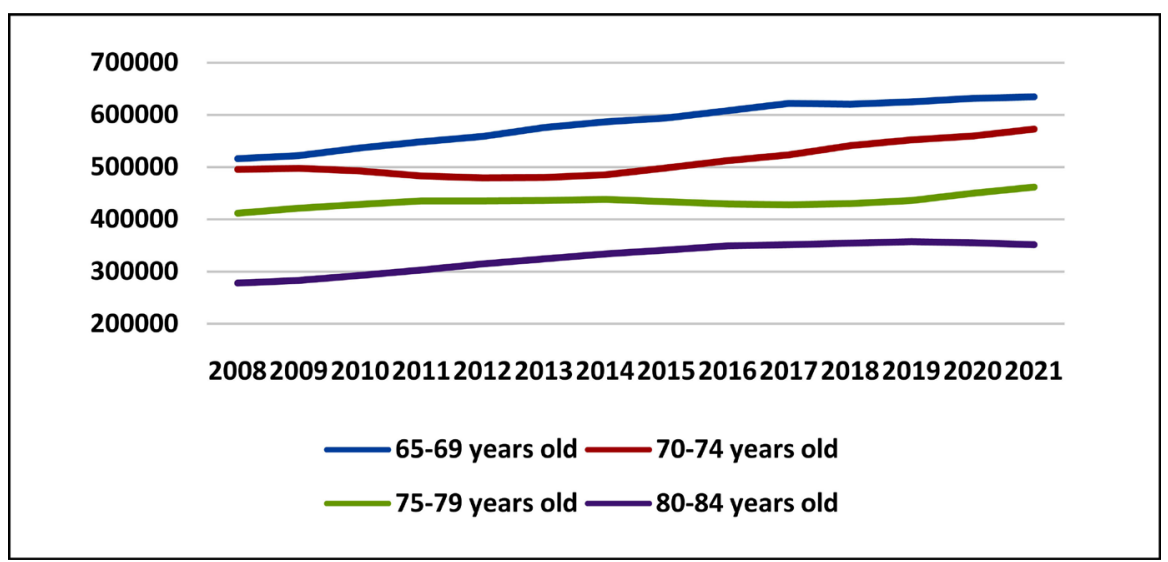

Figure 9. Annual estimates (until 2014) and projections (2015-2021) of the older resident population.

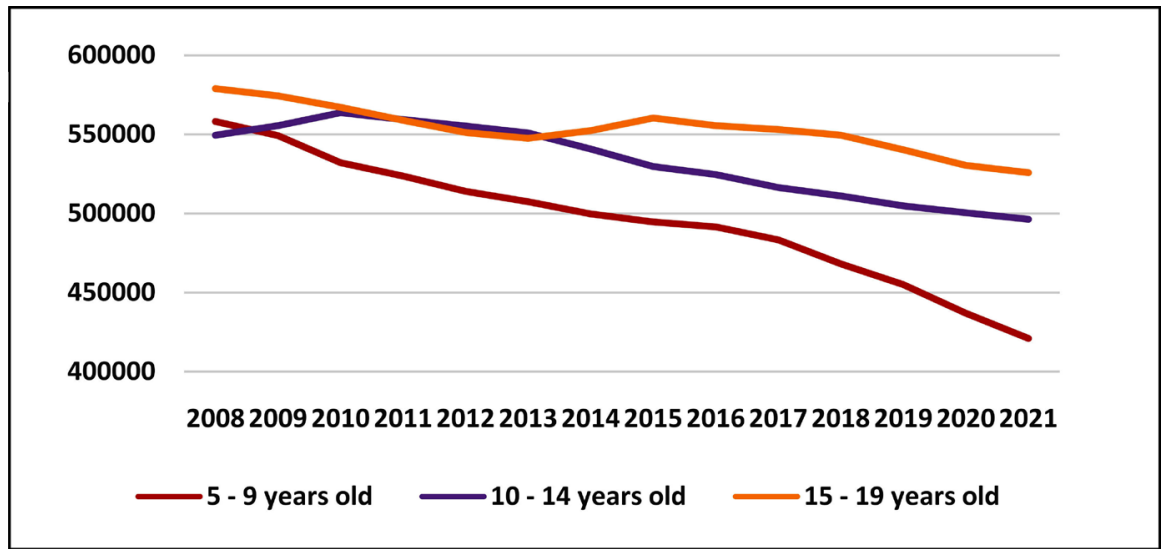

Figure 10. Annual estimates (until 2014) and projections (2015-2021) of the young resident population.

The young resident population in 2008 for the ages of 5 - 9, 10 - 14 and 15 - 19 was respectively 558,154,549,560 and 578,841. In the year of 2015 those numbers dropped to $494,705,529,762$ and 560,363 . By the official projections [6] this significant decrease will continue, reaching 420,937, 496,415 and 525,846 in 2021.

The population ageing experienced in Portugal is summarized by the Dependency Rates showed in Figure 11.

\subsection{Comparison of the Student and Resident Populations}

Now we will make the comparisons between the numbers of enrolled students, studied in Section 3, and the numbers of resident population, studied above in this section.

For the enrolled student population we will consider only the green and blue scenarios according to Section 3, the respective data are summarized next.

Figure 12 and Figure 13 show the evolution of the total number of students enrolled in the period of 2007/08-2014/15 and the projection for the period of 
2015/16-2020/21 for the green and blue scenarios respectively, according to Section 3 .

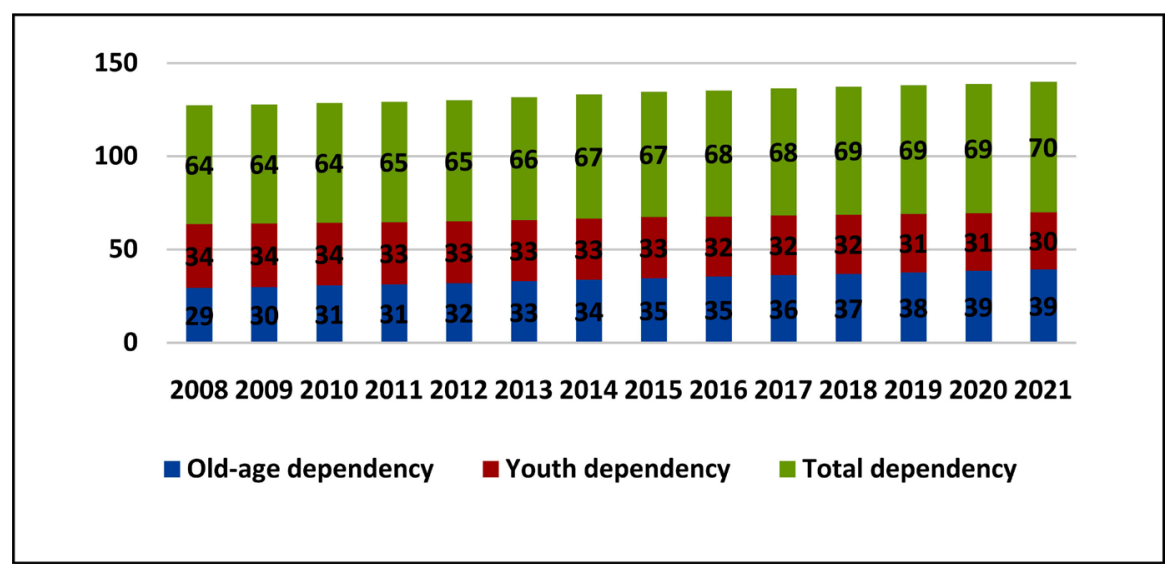

Figure 11. Total dependency $=(($ Population under age $20+$ Population aged 65 years and over $) /($ Population aged 20 to 64 years $)) \times 100$. Old-age dependency $=($ Population aged 65 years and over/Population aged 20 to 64 years $) \times 100$. Youth dependency $=($ Population under age 20/Population aged 20 to 64 years) $\times 100$.

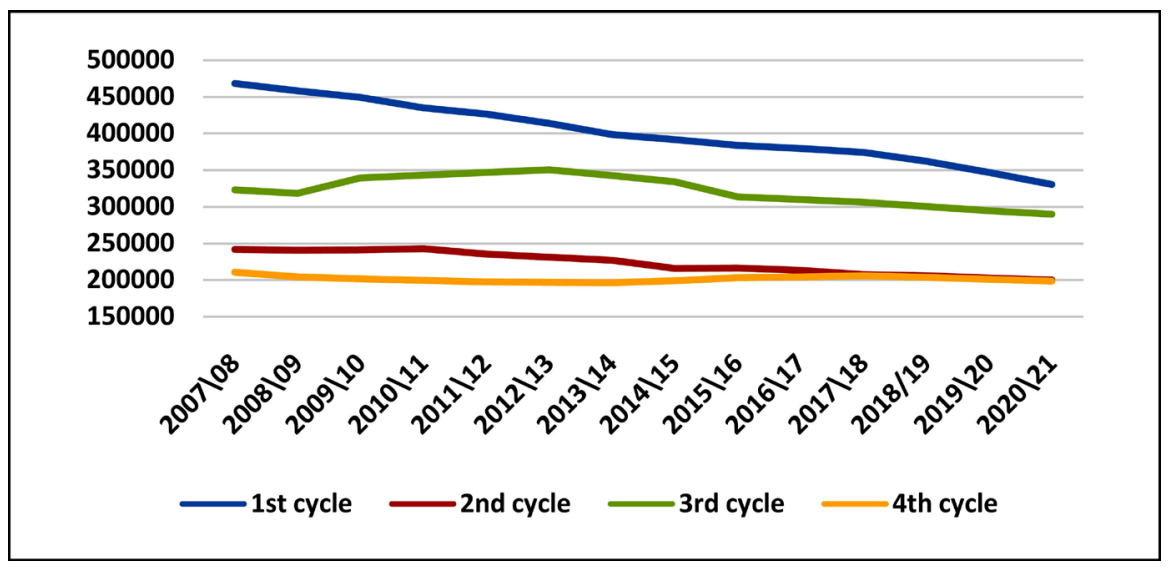

Figure 12. Evolution of the total number of students enrolled (2007/08-2014/15) and Projection of the number of students by the green scenario (2015/16-2020/21).

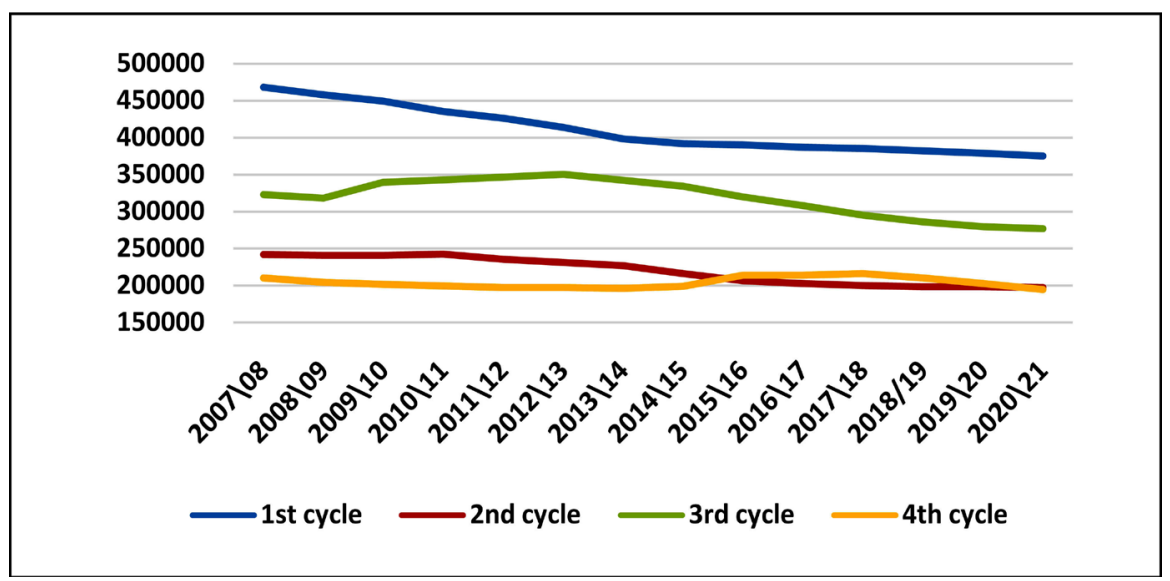

Figure 13. Evolution of the total number of students enrolled (2007/08-2014/15) and Projection of the number of students by the blue scenario (2015/16-2020/21). 
The two scenarios project a decrease in the student population until 2021. This can be seen in details in Table 5 .

The drop in these numbers is consequence of demographic decrease in view of the ageing population as we will observe next.

The first comparison is between the student population and the total resident population. This is done in Figure 14 and Figure 15, which show the ratio between the number of students and to the total population in the period 20082014 according to [2] and [6], and for 2015/16-2020/21 according to green and blue scenarios.

We observe that in 2008 the total number of enrolled students was $11.77 \%$ of the resident population, in 2014 was $11.22 \%$ and the projection for 2021 is $10.04 \%$ for the green scenario and $10.28 \%$ for the blue one.

For the number of students in the $2^{\text {nd }}$ and $4^{\text {th }}$ cycles the percent ratio are practically constant in all the period with the value of $2 \%$ for the both scenarios, green and blue.

The situation is quite different for the $1^{\text {st }}$ cycle, in 2008 was $4.43 \%$, in 2014 was $3.84 \%$ and the projection for 2021 is $3.26 \%$ by the green scenario and $3.69 \%$ by

Table 5. Projections according green and blue scenarios.

\begin{tabular}{|c|c|c|c|c|c|c|c|c|}
\hline \multirow{2}{*}{ Years } & \multicolumn{4}{|c|}{ Green scenario } & \multicolumn{4}{|c|}{ Blue scenario } \\
\hline & Cycle 1 & Cycle 2 & Cycle 3 & Cycle 4 & Cycle 1 & Cycle 2 & Cycle 3 & Cycle 4 \\
\hline $2015 / 16$ & 383,554 & 216,660 & 313,314 & 203,374 & 390,366 & 206,295 & 319,796 & 213,925 \\
\hline $2016 / 17$ & 379,383 & 213,201 & 309,995 & 204,505 & 386,966 & 202,848 & 308,122 & 213,791 \\
\hline $2017 / 18$ & 374,214 & 207,439 & 305,925 & 205,790 & 385,453 & 200,334 & 295,187 & 216,457 \\
\hline $2018 / 19$ & 361,936 & 205,639 & 300,353 & 203,546 & 382,293 & 198,535 & 286,206 & 210,314 \\
\hline $2019 / 20$ & 346,925 & 202,944 & 294,296 & 201,029 & 378,754 & 198,395 & 279,526 & 202,781 \\
\hline $2020 / 21$ & 330,235 & 200,109 & 289,838 & 198,473 & 375,183 & 197,242 & 276,689 & 194,610 \\
\hline Total cycles & $2,176,247$ & $1,245,992$ & $1,813,721$ & $1,216,717$ & $2,299,015$ & $1,203,649$ & $1,765,526$ & $1,251,878$ \\
\hline $\begin{array}{c}\text { Total } \\
\text { scenarios }\end{array}$ & & 6,452 & 2,677 & & & 6,520 & 0,068 & \\
\hline
\end{tabular}

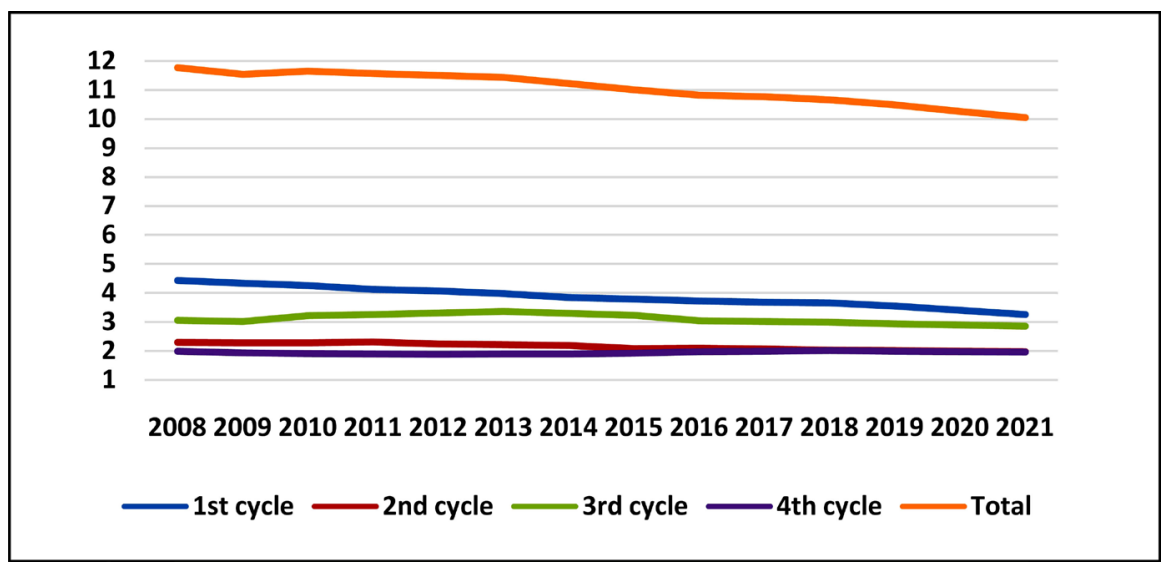

Figure 14. Percentage of enrolled students (total and by cycles) over the total population (by the official estimates for 2008-2014 and by the green scenario for 2015/16-2020/21). 


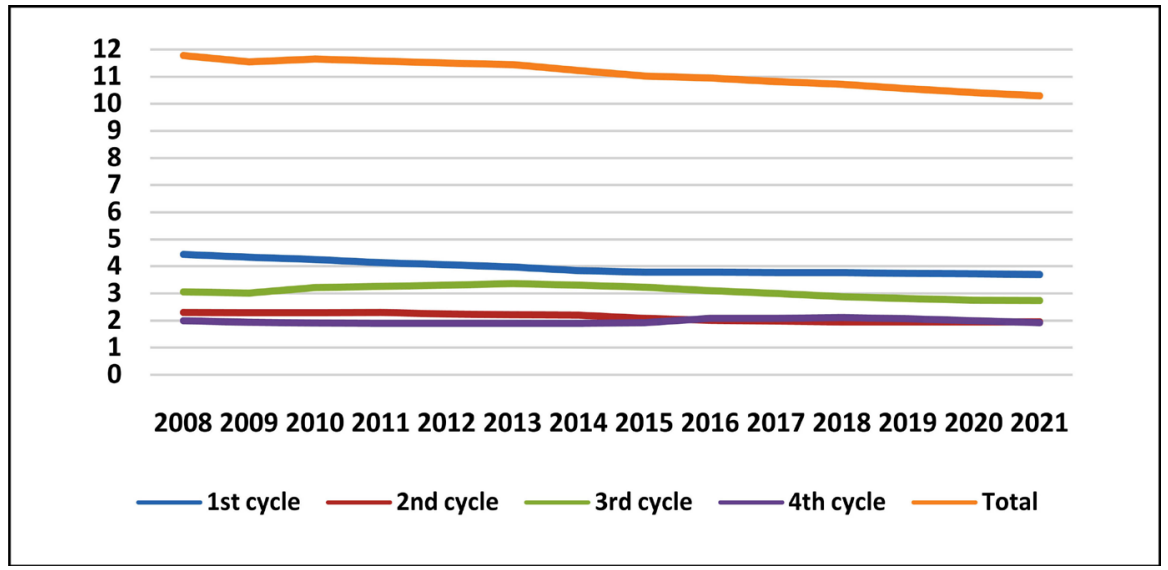

Figure 15. Percentage of enrolled students (total and by cycles) by the total population (by the official estimates for 2008-2014 and by the blue scenario for 2015/16-2020/21).

the blue.

While for the $3^{\text {rd }}$ cycle we have $3.05 \%$ in 2008 , 3.3\% in 2014 and projections of $2.85 \%$ and $2.73 \%$ for the green and blue scenarios, respectively.

It is very interesting to observe that the cycles behavior can indicate a kind of wave evolution. Probably more studies are necessary to corroborate this.

The usual age for the students of elementary and secondary studies in Portugal is between 6 and 17, so we consider this range in the next comparison.

In Figure 16 we have the ratio between the number of students and the population with age 6 - 17 considering the historical data (until 2014) and the projections according to the blue scenario (the estimates for the green are very close).

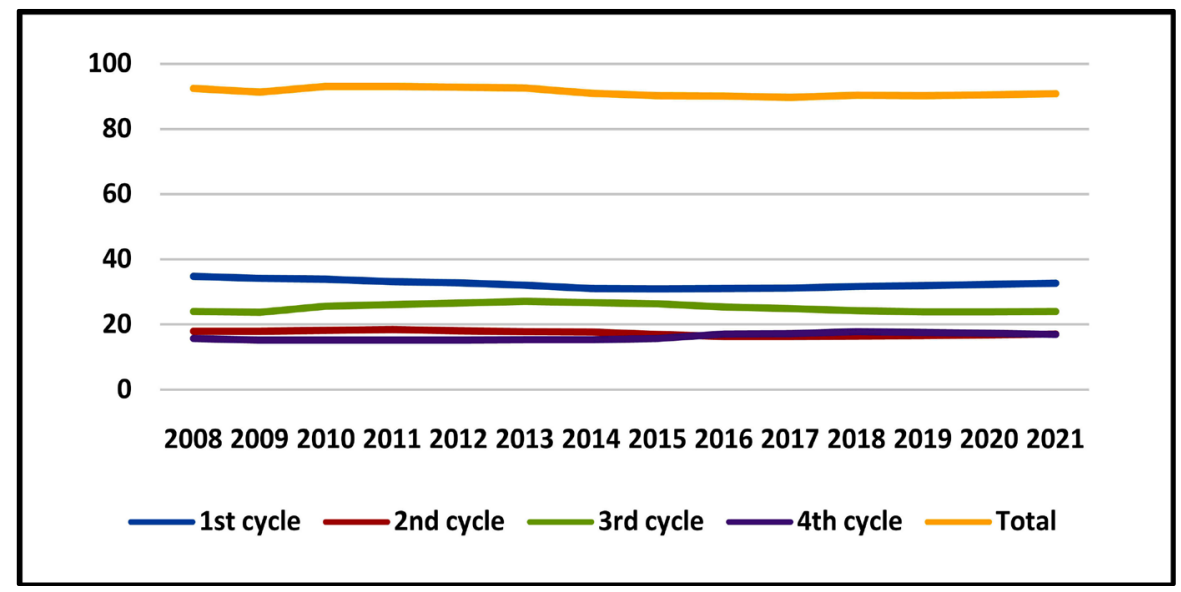

Figure 16. Percentage of enrolled students (total and by cycles) for the population of age 6-17 (by the official estimates for 2008-2014 and by the blue scenario for 2015/162020/21).

We observe a small decrease in the enrollment rate over all the range. The numbers are $92.43 \%$ for 2008, 90.94\% for 2014 and a projection of $90.79 \%$ for 2021 .

Considering by cycles, we observe about $15 \%-17 \%$ for the $2^{\text {nd }}$ and $4^{\text {th }}$ over all the period. For the $1^{\text {st }}$ cycle we had $34.79 \%$ in $2008,31.11 \%$ in 2014 and a projection of $32.63 \%$ for 2021 . For the $3^{\text {rd }}$ cycle, $24.01 \%$ in $2008,26.74 \%$ and the pro- 
jection for 2021 is $24.06 \%$.

We observe that the enrollment does not depend on the age structure of the population. We consider that this small decrease is due to the economic situation of the country.

\section{Conclusions}

According to the projections, the greatest drop in the number of enrolled students in continental Portugal in the next years will occur in basic schooling, whose main impacts are already felt on the $1^{\text {st }}, 2^{\text {nd }}$ and $3^{\text {rd }}$ cycles of studies. Despite the recent extension of compulsory studies to 18 years of age, secondary schooling also reveals a tendency of decrease in the number of students from $2017 / 18$ on. Although the number of students enrolled in scientific and humanistic courses aiming higher education has increased in the last years, the total number of students in professional courses has decreased.

The main reason for this drop is the population ageing, which is directly related to the decrease in birth rates.

The projections presented in this article are an important working tool to educational, social and economic plans for the next years, especially in what concerns to implement measures in education, to increase the birth rate, to settle resident population and to develop repopulation policies, among others.

\section{References}

[1] Pereira, E., Rosa, C. and Silva, J.A.L. (2014) A Model Structured in Classes for the Study of Student Population Evolution. Journal of Shanghai University (Natural Science Edition), 20, 127-137. http://www.oriprobe.com/journals/shdxxb/2014_2.html

[2] General Direction of Statistics of the Ministry of Education and Science in Portugal (DGEEC) (2007/2008-2014/2015) Education Statistics. http://www.dgeec.mec.pt/np4/96/

[3] Castro, L., Duarte, J., Nóvoas, D. and Martins, P. (2013) Projection Model for the Number of Students in Portugal-Effects of the Extension of Compulsory, 1-6. http://www.dgeec.mec.pt/np4/PREVISOES/

[4] General Direction of Statistics of the Ministry of Education and Science in Portugal (DGEEC) (2016) Projection for the Number of Students in Portugal by Regions, 2015-2021. Portugal. http://www.dgeec.mec.pt/np4/PREVISOES/

[5] Education Planning and Statistics of Portugal (INE) (2009) 50 Years of Education Statistics. Vol. 1, 2, 3. http://www.dgeec.mec.pt/np4/172/

[6] Statistics of Portugal (INE), Population Estimates, Population Projections (20122060), Portugal. https://www.ine.pt/xportal/xmain?xpgid=ine_main\&xpid=INE

[7] Castro, L., Duarte, J., Nóvoas, D. and Martins, P. (2014) Projection for the Number of Students in Portugal by Regions, 2013-2019, 1-15.

http://www.dgeec.mec.pt/np4/PREVISOES/ 
Submit or recommend next manuscript to SCIRP and we will provide best service for you:

Accepting pre-submission inquiries through Email, Facebook, LinkedIn, Twitter, etc. A wide selection of journals (inclusive of 9 subjects, more than 200 journals)

Providing 24-hour high-quality service

User-friendly online submission system

Fair and swift peer-review system

Efficient typesetting and proofreading procedure

Display of the result of downloads and visits, as well as the number of cited articles Maximum dissemination of your research work

Submit your manuscript at: http://papersubmission.scirp.org/

Or contact jss@scirp.org 